7 - ORIGINAL ARTICLE

WOUND HEALING

\title{
Use of low-power laser to assist the healing of traumatic wounds in rats ${ }^{1}$
}

\author{
Fernanda Camila Ferreira da Silva Calisto ${ }^{\mathrm{I}}$, Sérgio Luís da Silva Calisto ${ }^{\mathrm{II}}$, Amanda Pires de Souza ${ }^{\mathrm{III}}$, Cristiane Miranda França ${ }^{\mathrm{IV}}$, \\ Ana Paula de Lima Ferreirav ${ }^{\mathrm{v}}$, Márcia Bento Moreira ${ }^{\mathrm{VI}}$
}

DOI: http://dx.doi.org/10.1590/S0102-865020150030000007

IFellow Master degree, Postgraduate Program in Health and Biological Sciences, Nucleus for Experimental Surgery Laboratory, Federal University of San Francisco Valley (UNIVASF), Petrolina-PE, Brazil. Intellectual and scientific content of the study, acquisition and interpretation of data, manuscript writing.

IISpecialist, General Surgery, University Hospital, Petrolina-PE, Brazil. Acquisition of data, technical procedures.

III Graduate student, School of Medicine, Nove de Julho University (UNINOVE), Sao Paulo-SP, Brazil. Technical procedures.

${ }^{\text {Iv }} \mathrm{PhD}$, Associate Professor, Oral Pathology Department and Post-Graduation Program in Biophotonics Applied to Health Sciences, Nove de Julho University Universidade, UNINOVE, Sao Paulo-SP, Brazil. Morphometric and statistical analysis, technical procedures.

vPhD, Associate Professor, Department of Physiotherapy, Federal University Pernambuco (UFPE), Recife-PE, Brazil. Technical procedures.

${ }^{\mathrm{V}} \mathrm{PhD}$, Full Professor, Department of Veterinary Surgery and Anesthesiology, School of Veterinary Medicine and Animal Science, UNIVASF, PetrolinaPE, Brazil. Conception and design of the study, interpretation of data, critical revision.

\begin{abstract}
PURPOSE: To investigate the morphological aspects of the healing of traumatic wounds in rats using low-power laser.

METHODS: Twenty four non isogenic, young adult male Wistar rats (Rattus norvegicus) weighing between 200 and $300 \mathrm{~g}$ was used. The animals were randomly distributed into two groups: Control (GC) and Laser (GL), with 12 animals each. After shaving, anesthesia was performed in the dorsal region and then a surgical procedure using a scapel was carried out to make the traumatic wound. GL received five sessions of laser therapy in consecutive days using the following laser parameters: wavelength $660 \mathrm{~nm}$, power $100 \mathrm{~mW}$, dose $10 \mathrm{~J} / \mathrm{cm}^{2}$. The wounds were evaluated through measurement of the area and depth of the wound (MW) and histological analysis (HA).
\end{abstract}

RESULTS: When comparing the GC with the GL in MW there was a difference in area $(p<0.001)$ and depth $(p=0.003)$ measurement of the wounds in GL. The laser group presented more epithelization than GC $(p=0.03)$. The other histological parameters were similar. CONCLUSION: The healing of wounds in rats was improved with the use of the laser.

Key words: Laser Therapy. Wound Healing. Rats. 


\section{Introduction}

A wound is the loss of continuity of a body tissue with varied etiology, which can reach from the epidermis to deeper structures such as muscles, tendons and bones. Wound treatment is probably one of the oldest areas of medicine ${ }^{1}$.

Classification of wounds includes the evolution (acute or chronic); the presence of infection (uncontaminated clean, clean contaminated, contaminated or dirty and infected); the depth (stage I, II, III and IV) and/or the cause (intentional or unintentional and surgical or traumatic) $)^{2,3}$.

Acute traumatic wounds can result in injuries with extensive skin loss and damage to tissue viability or exposure of important organs. Wounds comprise a major cause for the use of hospital emergency services: 11 million patients treated annually in emergency departments in the United States are for this cause ${ }^{2}$.

The population most affected by traumatic wounds is economically active, aged 20 to 59 years, resulting in a significant social and economic impact, because during the treatment period these individuals are restricted from their work activities, and even after recovery, chronic sequelae, as aesthetic and functional limitation, may be present $t^{2,3}$.

The treatment and management of traumatic wounds depends on their characteristics, extent, the general conditions of the patient and the conditions of care. Daily cleaning, debridement and even surgical reconstruction are common practices and there may be an association with other adjuvant treatments such as hyperbaric oxygen therapy, negative pressure and the use of hydrocolloids and gels ${ }^{5-9}$.

Irradiation with low-power laser has been used in clinical practice as a complementary tool to enhance healing with positive cosmetic and anti-inflammatory effects in various types of injuries, such as epithelial, muscle and bone repair.

The biomodulator effect of the laser is based on the theory that photon energy is absorbed by a photoreceptor cell, for example oxyhemoglobin, hemoglobin, cytochrome c oxidase, and melanin cells, since the energy of photons is absorbed by these cells. The molecule assumes a electronically excited state and that energy is converted into chemical energy within the cell. These events are biomodulated in the different types of cells involved in tissue repair and include increased neoangiogenesis, changes in cytokine synthesis and aid in the conversion of fibroblasts in myofibroblasts ${ }^{10-16}$.

The objective of this study of the macro and microscopic effects of laser therapy was to investigate the closure of traumatic wounds in rats.

\section{Methods}

This study was approved by the Ethics Committee and Ethics Studies and Research (CEDEP)/Ethics Committee on Animal Use (CEUA) of the Federal University of San Francisco Valley - UNIVASF, under protocol number 0001/170913.

The sample consisted of 24 male Wistar rats (Rattus norvegicus albinus), weighing between 200 and 300 grams. The animals came from the central vivarium of the University and remained in adaptation for six days in the Nucleus for Experimental Surgery laboratory, of the Federal University of San Francisco Valley (UNIVASF).

\section{Surgery and experimental groups}

The animals were anesthetized by intraperitoneal injection of ketamine and xylazine ( $80 \mathrm{mg} / \mathrm{kg}$ and $10 \mathrm{mg} / \mathrm{kg}$ body weight), and tramadol hydrochloride (4 mg/kg body weight). Once anesthetized, the dorsal region of each animal was sterilized with alcohol-iodine prior to trichotomy. The tip of a scalpel was used to make a longitudinal incusion $(5 \times 3 \mathrm{~cm})$ at a depth of $6 \mathrm{~mm}$ along the right portion of the back of the animal and the fragment removed to expose the muscle and laceration of the dorsal muscle fibers to similate a traumatic wound. A pilot study provided the standard for the operations and all operations were carried out by the same person.

After completion of surgery, animals were housed individually in polypropylene cages with standard food and water ad libitum, under controlled temperature and moisture with the light cycle automatically adjusted every 12 hours. And after recovery from anesthesia, the rats were randomly distributed into two groups, with 12 animals each:

- CG: control group, untreated, only subjected to handling and physical restraint of five sessions on consecutive days, simulating laser application;

- GL: Laser Group, treated with five applications of low level laser on consecutive days, using the following parameters: laser diode (Photon Laser III, DMC, São Carlos, Brazil), wavelength $660 \mathrm{~nm}$, visible red, power $100 \mathrm{~mW}$ power density per point of $10 \mathrm{~J} / \mathrm{cm}^{2}$ and irradiation time of 20 seconds per spot with a total dose of $2 \mathrm{~J} /$ dot.

\section{Macro and microscopic evaluation of the wound}

After inflicting the wound, all animals were subjected to an assessment on the first day (D1) and were reassessed on the sixth day (D6) after the end of each respective group procedures. 
The measurements of the wound were performed using a digital caliper with an accuracy of $0.01 \mathrm{~mm}$, from which the largest transverse (CT) and longitudinal lengths (CL) were collected from each lesion, where the product (CL x CT) of these measures resulted in the area expressed in $\mathrm{mm}^{2}$. The depth values were expressed in absolute display obtained using the lower shaft of the caliper, given in millimeters.

At the end of the sixth day the animals were euthanized with an overdose of anesthetic (4 times the dose required for analgesia) and then the fragments of skin were removed and fixed in $10 \%$ paraformaldehyde and embedded in paraffin and hematoxilia and eosin staining for performing routing histology. A pathologist blinded to the groups did two evaluations in different weeks. In cases of disagreement scores, a third evaluation was made.

After making the slides, the following histological parameters were analyzed: reepithelialization, intensity of inflammatory infiltrate, presence of granulation tissue and neoangiogenesis. The scores were established according to the methodology of Melo et al. ${ }^{13}$, namely: $(+1)=$ less than $10 \%$; $(+2)$ $=$ between 10 and 50\%; $(+3)=$ More than 50\%.

\section{Statistical analysis}

The original data were transferred to a database in Microsoft Excel (version 2010), where statistical tests were performed. Part of the statistical analysis was performed using the software program Statistical Package for Social Science version 10 (SPSS 10) for Windows. The Shapiro-Wilk test was used first to assess the normal distribution (Gauss) variables; then the Student t-test was applied to the values obtained from the measurements; scores were analyzed with the Wilcoxon test, and all tests were considered to be statistically significant at $\mathrm{p}<0.05$.

\section{Results}

During the protocols of the two groups, surgical procedures were carried out without complexities, with no deaths. Anesthetic recovery was satisfactory with maintenance of general health and appetite.

The macroscopic evaluation consisted of measurement of the wound area performed with calipers and expressed in graphics, as shown in Figure 1, which is the average of the averages of these areas assessed by Student $t$ test unpaired. It was observed that the areas were reduced in sixth day compared with the first day, and also that there was a difference between the groups $(p<0.001)$.

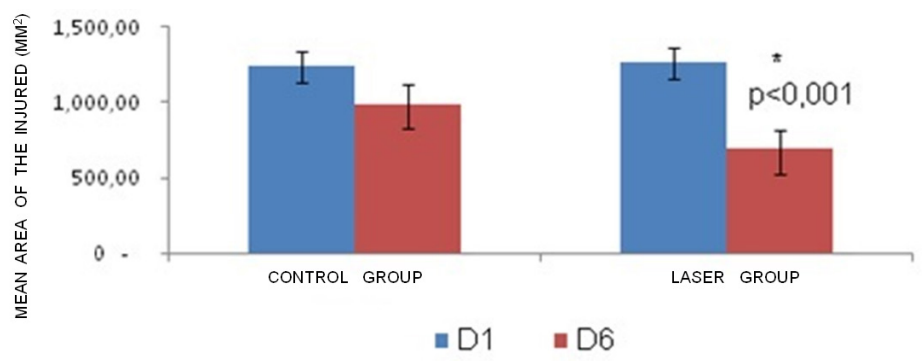

FIGURE 1 - Graph comparing the values of mean wound areas in the two periods studied showing the same decrease between days and a statistical difference between groups $(\mathrm{p}<0.001)$.

Regarding the depth of the wound, the laser group showed a decrease of the same in relation to the control group $(\mathrm{p}=$ 0.003, t Student test), as shown in Figure 2.

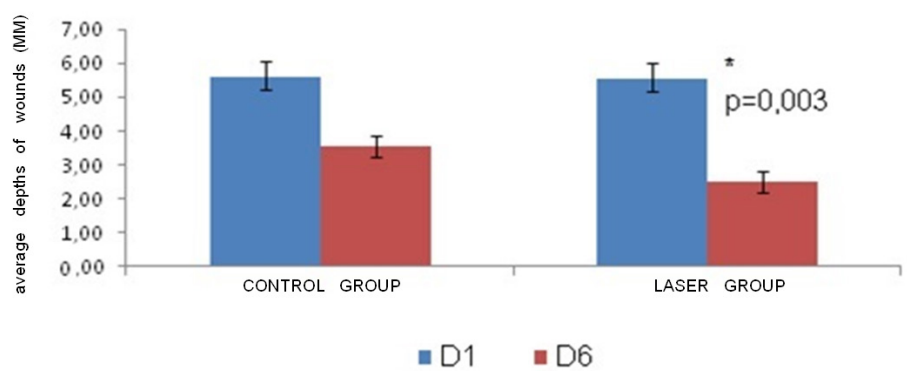

FIGURE 2 - Graph comparing the values of the depths of the wounds in the two periods studied showing that both groups underwent a decrease in the average depth of the wound on day 6 , and the laser group showed a statistically greater decrease $(\mathrm{p}=0.003, \mathrm{t}$ Student test $)$.

Regarding the descriptive microscopic analysis, histological sections revealed that on day 1 , the traumatic wounds of both groups were in the inflammatory phase of repair; inflammation of moderate to intense. On day 6 , the wounds were in the proliferative phase of repair, showing granulation tissue with angiogenesis and proliferation of fibroblasts, with complete or almost complete reepithelialization, especially in the laser group of animals (Wilcoxon test $-\mathrm{p}=0.03$ ) wounds (Figure 3 ). 


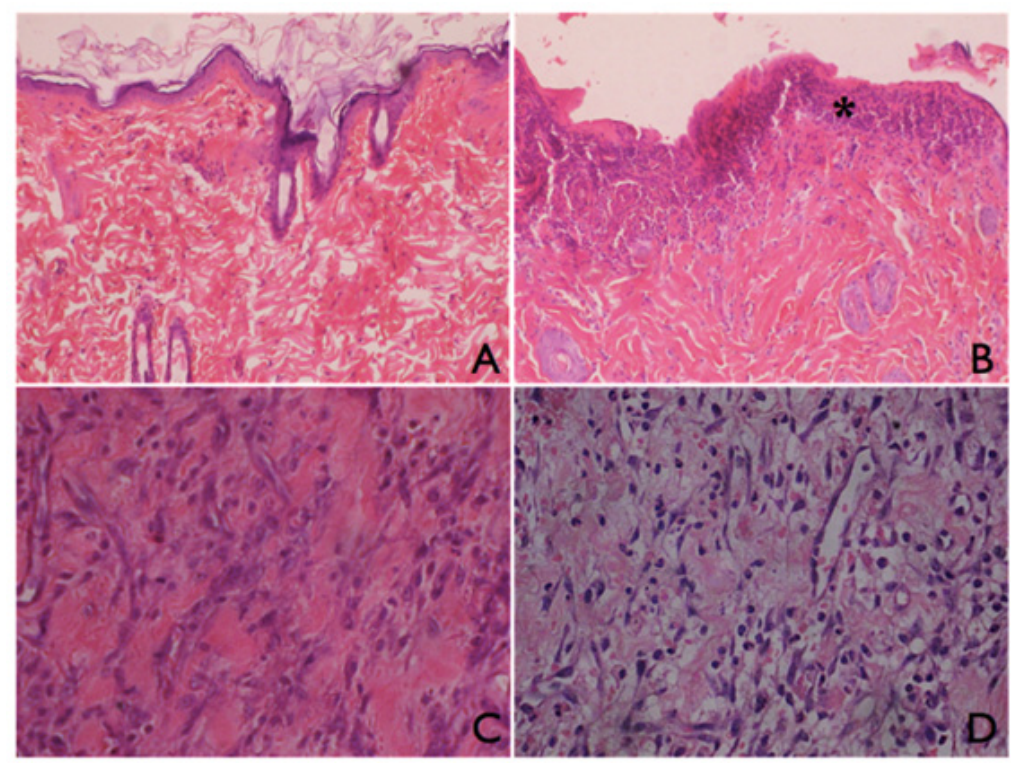

FIGURE 3 - Photomicrograph of histological section of the wounds on day 6 of GL (A) showing complete epithelialization, with a thin epithelial layer, keratin plates and skin appendages. In the same period, the wounds of the GC (B) showed acute inflammatory infiltrate $(*)$. Granulation tissue was similar in both the laser group $(\mathbf{C})$ and control group (D).

The parameters of inflammatory infiltrate, vascular with a statistical difference in the reepithelialization (Table 1) proliferation and fibroblasts were similar between groups, variable.

TABLE 1 - Table showing the correspondence of histological scores and the amount of wounds The CG and GL, on day 6 (after the protocol in each group):

\begin{tabular}{c|c|c|c|c|c|c|c|c}
\hline \multirow{2}{*}{ Score } & \multicolumn{2}{|c|}{ Reepithelialization } & \multicolumn{2}{c|}{ Inflammatory infiltrate } & \multicolumn{2}{c|}{ Angiogenesis } & \multicolumn{2}{c}{ proliferation of fibroblasts } \\
\cline { 2 - 10 } & Control & $\begin{array}{c}\text { Laser } \\
(\mathrm{p}=0,03)\end{array}$ & Control & Laser & Control & Laser & Control & Laser \\
\hline+1 & 4 & 3 & 0 & 2 & 10 & 11 & 10 & 0 \\
\hline+2 & 5 & 7 & 8 & 8 & 0 & 1 & 0 \\
\hline+3 & 1 & 2 & 2 & 2 & 0 & 0 & 0 & 1 \\
\hline
\end{tabular}

\section{Discussion}

The present study demonstrated the use of laser in the healing of traumatic wounds with secondary intention healing. This finding was confirmed by both clinical measures and by histological evaluation.

These findings corroborate with the literature, where the use of the laser increases wound contraction with apparent acceleration of the repair process and delineation of visible scar scabbing and raised edges and reddish center, due to the presence of blood flow in the treated area ${ }^{13}$, due to the granulation tissue ${ }^{15}$.

The histological analysis found increased reepithelialization in the animals that received laser, indicating progression of almost- full to full and regular healing and the normal presence of skin appendages. This finding is important because the epithelial barrier prevents the installation of infectious processes, which constitute one of the common complications of wounds ${ }^{2,3}$.

In the study by Carvalho et al. ${ }^{11}$ the wounds were sutured and healed by first intention, therefore the number of inflammatory cells in the group irradiated for seven days was less evident. In the present work, the wounds were larger in size and healed by secondary intention and reduction of the inflammatory infiltrate was similar between GL and GC groups, indicating that laser therapy is effective in both healing processes, either by modulating the inflammatory process in repair by first intention, and increasing epithelialization repair by secondary intention ${ }^{11}$. 
The laser parameters were chosen based on literature, which indicates that doses of between 1 and $10 \mathrm{~J} / \mathrm{cm}^{2}$ are the most favorable for repair biomodulation ${ }^{17}$. Lower doses would not take effect and might induce larger doses inhibiting cell activity, delaying the closing of the wound ${ }^{10,15-17}$.

From the results it can be stated that the laser is an adjunct in the treatment of complex wounds, accelerating the closure of the same and favoring the restoration of morphofunctional tissue.

\section{Conclusion}

Laser therapy can be an adjunct to the healing of traumatic wounds, especially by accelerating reepithelialization of traumatic wounds.

\section{References}

1. Coltro PS, Ferreira MC, Batista BPSN, Nakamoto HA, Milchesi DA, Junior PT. Role of plastic surgery on the treatment complex wounds. Rev Col Bras Cir. 2011;38(6):381-6. PMID:22267134.

2. Mioton LM, Jordan SW, Hanwright PJ, Bilimoria KY, Kim JY. The Relationship between preoperative wound classification and postoperative infection: a multi-institutional analysis of 15.289 patients. Arch Plast Surg. 2013 Sep;40(5):522-9. doi.org/10.5999/ aps.2013.40.5.522.

3. Cardoso T, Almeida M, Friedman ND, Aragão I, Costa-Pereira A, Sarmento AE, Azevedo L. Classification of healthcare-associated infection: a systematic review 10 years after the first proposal. BMC Med. 2014 Mar;12:40. doi: 10.1186/1741-7015-12-40.

4. Eliya-Masamba MC, Banda GW. Primary closure versus delayed closure for non bite traumatic wounds within 24 hours post injury. Cochrane Database Syst Rev. 2013:22(10):CD008574. doi: 10.1002/14651858.CD008574.pub3.

5. Bruhin A, Ferreira F, Chariker M, Smith J, Runkel N. Systematic review and evidence based recommendations for the use of Negative Pressure Wound Therapy in the open abdomen. Int J Surg. 2014 Aug 28;12(10):1105-14. doi: 10.1016/j.ijsu.2014.08.396.

6. Pinto ARC, Brazileiro DA, Da Silva VC. O conhecimento da equipe de enfermagem sobre as medidas preventivas das úlceras por pressão: uma realidade? Rev Rede Cuidados Saúde, 2013:7(2):1-11. doi.org/10.1590/S0103-21002008000200012.

7. Reis DBD, Peres GA, Zuffi FB, Ferreira LA. Cuidados às pessoas com úlcera venosa: percepção dos enfermeiros da estratégia de saúde da família. Rev Min Enferm. 2013:17(1):102-12.

8. Perdrizet GA. Principles and practice of hyperbaric medicine: a medical practitioner's primer, part II. Conn Med. 2014;78(7):389402. PMID: 25195304.

9. Campbell N, Campbell D. A retrospective, quality improvement review of maggot debridement therapy outcomes in a foot and leg ulcer clinic. Ostomy Wound Manage. 2014 Jul;60(7):16-25. PMID: 25019246.

10. Avci P, Gupta A, Sadasivam M, Vecchio D, Pam Z, Pam N, Hamblin MR. Low-level laser (light) therapy (LLLT) in skin: stimulating, healing, restoring. Semin Cutan Med Surg. 2013;32(1):41-52. PMID: 24049929.
11. Carvalho KC, Nicolau RA, Maia AL, Barja RP, Sá HP, Santo LA, Rocha GM. Study of the strength of healing skin of rats treated with phototherapy in laser. ConScientiae Saúde, 2010:9(2):179-86. PMID: 233756617.

12. Gonçalves RB, Marques JC, Monte-raso VV, ZamariolI A, Carvalho CL, Fazan VPS, Tavares, MR. Effects of low-power laser on injured rat sciatic nerve regeneration. Fisioter Pesq. 2010;17(1):34-9. doi. org/10.1590/S1809-29502010000100007.

13. Melo VAD, Anjos, DCSD, Albuquerque JR, Melo DB. Effect of low level laser on sutured wound healing in rats. Acta Cir Bras. 2011;26(2):129-34. doi.org/10.1590/S0102-86502011000200010.

14. Marcos RL, Leal Junior EC, Messias FM, de Carvalho MH, Pallotta RC, Frigo L, dos Santos RA, Ramos L, Teixeira S, Bjordal JM, Lopes-Martins RÁ. Infrared $(810 \mathrm{~nm})$ low-level laser therapy in rat achilles tendinitis: a consistent alternative to drugs. Photochem Photobiol. 2011 Nov-Dec;87(6):1447-52. doi: 10.1111/j.17511097.2011.00999.x.

15. Silva EB, Maniscalco CL, Ésper GVZ, Guerra RR, Kerppers II. Macro and microscopic analysis of island skin grafts after low-level laser therapy. Rev Col Bras Cir. 2013:40(1):44-8. PMID: 23538538.

16. Yasukama A, Ohrui H, Koyama Y, Nagai M. The effect of LLLT with $\mathrm{HeNe}$ Laser on operative wound healing in rat model. J Vet Med Sci. 2007;69(8):799-806. PMID: 17827885.

17. Demidova-Rice TN, Salomatina EV, Yaroslavsky AN, Herman IM, Hamblin MR. Low-level light stimulates excisional wound healing in mice. Lasers Surg Med. 2007;39(9):706-15. PMID: 17960752.

\section{Acknowledgement}

To graduate students Davi Freire and Dália Machado for help with technical procedures.

\section{Correspondence:}

Fernanda Camila Ferreira da Silva Calisto

Rua Demócrito de Souza Filho, 323-B1 B/503

50610-120 Recife - PE Brasil

fernandacamilacalisto@gmail.com

Received: Nov 19, 2014

Review: Jan 20, 2015

Accepted: Feb 18, 2015

Conflict of interest: none

Financial source: Pernambuco Foundation for Science and Technology (FACEPE-n ${ }^{\circ}$ : IBPG-1373-4.08/12)

IResearch performed at Nucleus for Experimental Surgery Laboratory, Federal University of San Francisco Valley (UNIVASF), Petrolina-PE, Brazil. 